DOI: 10.20472/IAC.2018.035.045

\title{
CRISTIANA TUDOR
}

Bucharest University of Economic Studies, Romania

\section{IMPLICATIONS OF EXTREME VALUE THEORY FOR STOCK MARKET INVESTMENTS}

\begin{abstract}
:
Young post-communist Eastern European equity are more vulnerable to external and internal shocks than more mature, developed markets. Also, previous studies have attested that generally the distribution of stock prices exhibits deviations from Gaussianity, including the so-called "heavy tails".

The higher degree of volatility encountered on these markets leads to the expectation that heavy-tailedness properties for stock returns will be more pronounced. In this research we attempt to confirm the fat/heavy tails hypothesis for a selection of 98 stocks listed on the Romanian Stock Market and we manage to accomplish this in a fairly large number of cases, both for the left and the right side of the distribution of daily logarithmic returns. Next, we try to establish whether "booms" are more likely than "crashes" for each company in the sample. Robustness checks via bootstraping enable the rejection or acceptance of this hypothesis with $95 \%$ confidence. The empirical results have important implications both for practioners via portfolio investment decisions and also for academic research i.e. value-at-risk or asset alocation models.
\end{abstract}

\section{Keywords:}

equity market, Eastern Europe, volatility, heavy-tails, portfolio decisions

JEL Classification: G15, G11, G14 